\title{
Assessing Wildlife Benefits and Carbon Storage from Restored and Natural Coastal Marshes in the Nisqually River Delta: Determining Marsh Net Ecosystem Carbon Balance
}

\begin{abstract}
Working in partnership since 1996, the U.S. Fish and Wildlife Service and the Nisqually Indian Tribe have restored 902 acres of tidally influenced coastal marsh in the Nisqually River Delta (NRD), making it the largest estuary-restoration project in the Pacific Northwest to date. Marsh restoration increases the capacity of the estuary to support a diversity of wildlife species. Restoration also increases carbon (C) production of marsh plant communities that support food webs for wildlife and can help mitigate climate change through long-term $\mathrm{C}$ storage in marsh soils.

In 2015, an interdisciplinary team of U.S. Geological Survey (USGS) researchers began to study the benefits of carbon for wetland wildlife and storage in the NRD. Our primary goals are (1) to identify the relative importance of the different carbon sources that support juvenile chinook (Oncorhynchus tshawytscha) food webs and contribute to current and historic peat formation, (2) to determine the net ecosystem carbon balance (NECB) in a reference marsh and a restoration marsh site, and (3) to model the sustainability of the reference and restoration marshes under projected sea-level rise conditions along with historical vegetation change. In this fact sheet, we focus on the main $\mathrm{C}$ sources and exchanges to determine $\mathrm{NECB}$, including carbon dioxide $\left(\mathrm{CO}_{2}\right)$ uptake through plant photosynthesis, the loss of $\mathrm{CO}_{2}$ through plant and soil respiration, emissions of methane $\left(\mathrm{CH}_{4}\right)$, and the lateral movement or leaching loss of $\mathrm{C}$ in tidal waters.
\end{abstract}

\section{Restoring and Preserving Coastal Marshes Could Help Reduce Atmospheric Carbon Concentrations}

Increasing concentrations of $\mathrm{CO}_{2}$ in the Earth's atmosphere are linked to changes in weather and climate around the globe. One way to mitigate these changes is to preserve, restore, and create ecosystems that remove large amounts of $\mathrm{C}$ from the atmosphere and sequester it in soil organic matter. Coastal marshes have the potential to be effective at storing $\mathrm{C}$, because fast-growing marsh plants extract $\mathrm{C}$ from the atmosphere through photosynthesis and store it in leaves and stems aboveground and roots belowground. Although much of the aboveground and some of the belowground material decomposes over time, enough organic material is preserved by the waterlogged conditions to have a build-up of $\mathrm{C}$ in most marshes. Under the right conditions, this build-up of $\mathrm{C}$ can create organic "peat" soils and store $\mathrm{C}$ for hundreds to thousands of years. Preventing marsh loss, as well as restoring coastal marshes, maximizes long-term $\mathrm{C}$ storage and provides additional ecosystem benefits, which are of great concern to naturalresource managers and policymakers.
A) Reference marsh during high tide in the spring. Water levels are just a few centimeters above the coastal plain, but can be up to a meter deep during particularly high tides in the winter. $B$ ) Reference marsh during low tide in the summer. C) Restoration marsh during low tide in the summer. High tides in the marsh being restored can be more than a meter above the marsh plain because, historically, these areas were previously isolated from tidal influence and had

\section{How Do You Measure Carbon Uptake in Tidal Marshes?}

\section{Measurements at the Nisqually River Delta}

For an accurate assessment of $\mathrm{C}$ uptake from the atmosphere and its storage above- and belowground in the NRD, it is necessary to collect data under a range of environmental conditions. To accomplish this, the USGS plans to establish two meteorological stations in the NRD to continuously measure atmospheric $\mathrm{C}$ exchange. One station is to be placed in a natural, undisturbed, or "reference" marsh, and the other in a "restoration" marsh, a historical marsh that was diked for agricultural use and then restored to tidal influence in 2009. The NECB from both marshes provides a means to compare carbon uptake rates, as well as quantify potential carbon stocks and storage for carbon markets. 


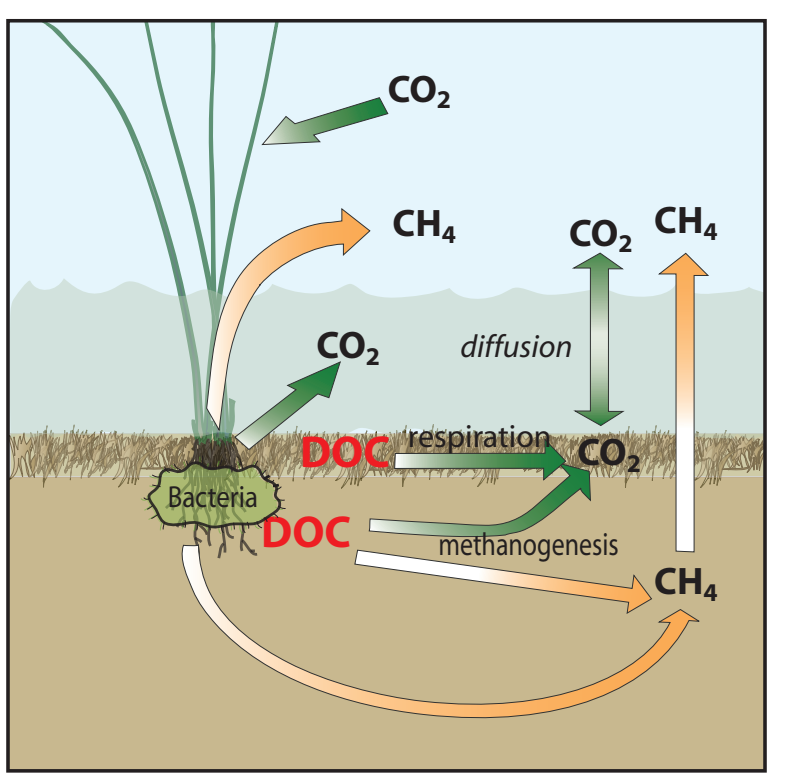

Net ecosystem carbon balance (NECB) is the net balance between carbon (C) inputs, such as carbon dioxide $\left(\mathrm{CO}_{2}\right)$ uptake through plant photosynthesis, and $\mathrm{CO}$ losses through plant and soil respiration; methane $\left(\mathrm{CH}_{4}\right)$ emissions; and the exchange of dissolved organic carbon (DOC), dissolved inorganic carbon (DIC), and sediment with tidal waters.

\section{Measuring Atmospheric Carbon Exchanges}

In order to determine the atmospheric component of the $\mathrm{NECB}$, we plan to deploy a suite of instrumentation at each site to measure $\mathrm{CO}_{2}$ uptake by plant photosynthesis, losses of $\mathrm{CO}_{2}$ by plant and soil respiration, and $\mathrm{CH}_{4}$ emissions. These instruments use continuous (10 times a second) measurements of

$$
\left|\begin{array}{c}
\text { Differences in plant type, } \\
\text { hydrology, salinity, and seasonality } \\
\text { affect carbon exchanges. }
\end{array}\right|
$$

$\mathrm{CO}_{2}$ and $\mathrm{CH}_{4}$ concentrations along with measurements of wind speed, which transports the gases, to quantify net atmospheric $\mathrm{C}$ exchanges. This information can help us understand how productivity differs between natural and recently restored coastal marshes, as well as how differences in plant type, hydrology,

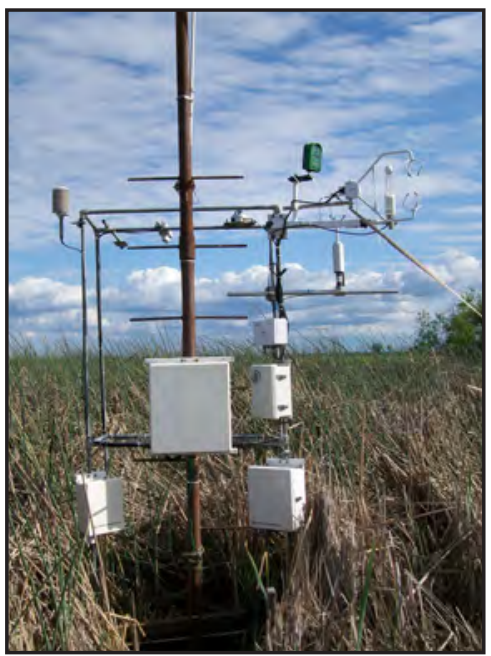

Meteorological tower: instrumentation includes carbon dioxide and methane analyzers; a wind anemometer; temperature, humidity, and radiation sensors; and a field camera. salinity, and seasonality affect atmospheric $\mathrm{C}$ exchanges.

Locations of meteorological stations are to be coordinated with the Billy Frank Jr. Nisqually National Wildlife Refuge management and the Nisqually Indian Tribe to minimize effects on the surrounding landscape. Necessary power systems, including solar panels and batteries, can be deployed in such a way to minimize marsh disturbance and preserve the scenic quality of the sites.

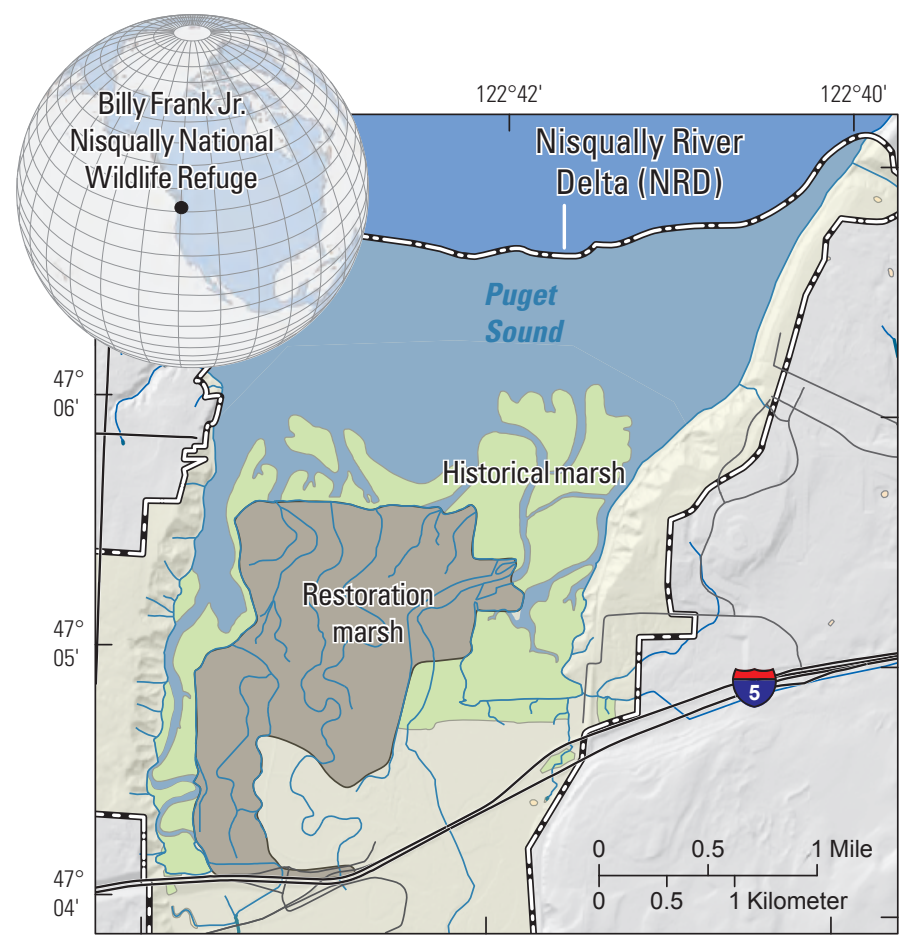

Location of the Nisqually River Delta (NRD). The green-shaded area represents the historical coastal marsh, and the gray-shaded area represents the marsh undergoing restoration.

\section{The Effects of Tides}

One difficulty in measuring net $\mathrm{C}$ uptake in coastal marshes is the effect of tides. Exchange of tidal waters can result in appreciable $\mathrm{C}$ loss, particularly when $\mathrm{C}$ taken up by plants through photosynthesis is exported as litter or dissolved organic carbon (DOC) to outflowing tidal waters. All such losses through the tidal exchange, and all gains from the delivery and settlement of DOC and dissolved inorganic carbon (DIC) in litter and sediments, must be quantified to estimate the NECB for each marsh.

To account for the tidal exchange of $\mathrm{C}$, two hydrology stations are planned to be established on the edge of the coastal marsh channel, next to the meteorological stations. These are needed to continuously measure the major forms of dissolved $\mathrm{C}$ and particulates in the volume of water exchanged. Together, the gaseous $\mathrm{C}$ measurements from the meteorological stations and the $\mathrm{C}$ measurements from the hydrologic stations can be used to estimate the net amount of $\mathrm{C}$ stored at the natural and restoration marsh sites.

\section{USGS Fact Sheet Authors:}

Frank Anderson, Brian Bergamaschi, Lisamarie Windham-Myers, Isa Woo,

Susan De La Cruz, Judith Drexler, Kristin Byrd, and Karen Thorne

\section{Funding Provided By:}

This project is funded by the United States Geological Survey Land Carbon Program and United States Fish and Wildlife Service, and leverages existing research from the National Aeronautics and Space Administration-Carbon Monitoring System program (Project \#: NNH14AY67I) and the Estuary and Salmon Restoration Program (Project \#: 13-1583P).

\section{For more information:}

Visit: http://www.werc.usgs.gov/nisquallycarbon or contact:

Lisamarie Windham-Myers: lwindham-myers@usgs.gov

\section{Partners:}

Billy Frank Jr. Nisqually National Wildlife Refuge:

http://www.fws.gov/refuge/nisqually/ 